\title{
Geographical diversity pattern in Iranian landrace durum wheat (Triticum turgidum) accessions using start codon targeted polymorphism and conserved DNA-derived polymorphism markers
}

\author{
Hiva Seyedimoradi, Reza Talebi*, Farzad Fayaz \\ Department of Agronomy \& Plant Breeding, Sanandaj Branch, Islamic Azad University, Sanandaj, Iran \\ ${ }^{*}$ Corresponding author, E-mail: srtalebi@yahoo.com
}

\begin{abstract}
Genetic diversity and relationships among 38 Iranian durum wheat accessions were analysed using conserved DNA-derived polymorphism (CDDP) and start codon targeted (SCoT) markers. A total of 10 CDDP and 10 SCoT primers were used to estimate genetic polymorphism among 38 durum wheat accessions. Comparatively, both CDDP and SCoT markers proved to be more effective and in terms of percentage of polymorphisms and polymorphic information content value were relatively similar. The average polymorphic information content value of CDDP was 0.39 which was relatively higher than those of SCoT where the respective values of polymorphic information content was 0.35 . Using the neighbor joining clustering method, CDDP and SCoT markers were used to generate dendrograms, which revealed that the durum accessions were clustered into three and two major groups, respectively. According to the present results, CDDP markers proved more informative in studying genetic diversity among durum accessions. In both marker types, low correlation between genetic distances and geographical origin in examined durum landrace accessions was found. However, accessions from the same geographical regions mostly showed more genetic similarity than those with origins far apart. The results demostrated that CDDP and SCoT markers are useful for genetic diversity analysis of durum accessions. This information is useful for future germplasm collection and efficient utilization of landrace durum germplasm in plant breeding.
\end{abstract}

Key words: CDDP, durum wheat, genetic diversity, SCoT.

Abbreviations: CDDP, conserved DNA-derived polymorphism; NJ, neighbor joining; PIC, polymorphic information content; SCoT, start codon targeted.

\section{Introduction}

Durum wheat (Triticum turgidum L. subsp. durum (Desf.) Husn) is an important cereal grain that is mainly used for human consumption. Durum is the primary wheat for pasta and semolina production and the second most cultivated wheat after bread wheat (Triticum aestivum L.) (Oliveira et al. 2012). Knowledge of the genetic diversity in crops is important in crop breeding programmes and in conservation of primary gene pool (Soleimaniet al. 2002). Low genetic diversity and narrow background of crop species can restrict development of superior genotypes that are tolerant to biotic and abiotic stresses (Talebi et al.2012). Cultivation of crops with different genetic background is an effective strategy for conservation and to reduce genetic vulnerability in crop improvment programmes (Smale et al. 2002; Mardi et al. 2011). Due to modern breeding, it has been suggested that genetic diversity in wheat and other crop species has been increasingly narrowed (Tanksley, McCouch 1997). A narrow genetic base is a problem in breeding for seed yield and for adaptation to biotic and abiotic stresses.

Iran is one of the leading centres for domestication of cereals and according to genetic and archaeological evidence, tetraploid wild emmer was domesticated in the Fertile Crescent around the 8th millennium BCE (Salamini et al. 2002; Oliveira et al. 2012). Genetic diversity in different durum wheat germplasm has been estimated using AFLP (Medini et al. 2005; Mardi et al. 2011), SSR and SSAP (Mardi et al. 2011) and AFLP markers (Maccaferri et al. 2007), but studies on the genetic diversity of Iranian landrace durum wheat are limited. The largest variability for yield and yield-related traits was recorded in Iranian durum wheat landraces, which is in agreement with its proximity to the Fertile Crescent, the origin for domestication of wheat (Harlan 1986; Fayaz et al. 2013). However, there is no information on genetic diversity patterns in Iranian durum wheat landraces at the molecular level.

In recent years, different molecular markers that generate polymorphism in conserved gene regions of the plant genome have been used, such as start codon targeted polymorphism (SCoT; Collard, Mackill 2009b) and 
conserved DNA derived polymorphism (CDDP; Collard, Mackill 2009a). The SCoT primers are based on conserved regions flanking the initiation codon sequences of genes and CDDPs are short primers to generate useful genetic markers across functional domains of well-characterised plant genes (Collard, Mackill 2009a; Collard, Mackill 2009b). These marker techniques has been successfully employed in genetic diversity analysis of several plants, such as chickpea (Pakseresht et al. 2013), wheat (Hamidi et al.2014), ramie (Satya et al. 2015) and jojoba (Heikrujam et al. 2015). The aim of the present study was to investigate the gentic diversity in Iranian landrace durum wheat accessions

Table 1. Sites of collection and sources of landrace durum accessions used in the present study

\begin{tabular}{|c|c|}
\hline Genotype number & Collection site/Source \\
\hline 1 & Azerbaijan, NW Iran \\
\hline 2 & Azerbaijan, NW Iran \\
\hline 3 & Azerbaijan, NW Iran \\
\hline 4 & Azerbaijan, NW Iran \\
\hline 5 & Kermanshah, W Iran \\
\hline 6 & Kermanshah, W Iran \\
\hline 7 & Kermanshah, W Iran \\
\hline 8 & Kermanshah, W Iran \\
\hline 9 & Kermanshah, W Iran \\
\hline 10 & Kermanshah, W Iran \\
\hline 11 & Kermanshah, W Iran \\
\hline 12 & Khorasan, NE Iran \\
\hline 13 & Khorasan, NE Iran \\
\hline 14 & Khorasan, NE Iran \\
\hline 15 & Khorasan, NE Iran \\
\hline 16 & Khorasan, NE Iran \\
\hline 17 & Khorasan, NE Iran \\
\hline 18 & Khorasan, NE Iran \\
\hline 19 & Khorasan, NE Iran \\
\hline 20 & Khorasan, NE Iran \\
\hline 21 & Khorasan, NE Iran \\
\hline 22 & Khorasan, NE Iran \\
\hline 23 & Khorasan, NE Iran \\
\hline 24 & Khuzestan, SW Iran \\
\hline 25 & Khuzestan, SW Iran \\
\hline 26 & Khuzestan, SW Iran \\
\hline 27 & Khuzestan, SW Iran \\
\hline 28 & Khuzestan, SW Iran \\
\hline 29 & Khuzestan, SW Iran \\
\hline 30 & Khuzestan, SW Iran \\
\hline 31 & CIMMYT, Mexico \\
\hline 32 & Iran \\
\hline 33 & Iran \\
\hline 34 & Iran \\
\hline 35 & Iran \\
\hline 36 & Italy \\
\hline 37 & Italy \\
\hline 38 & Khuzestan, SW Iran \\
\hline
\end{tabular}

and examine the relationships of geographical sources of these accessions with their genetic diversity pattern. This is the first study on the use of ScoT and CDDP markers for genetic diversity analysis in durum wheat.

\section{Materials and methods}

\section{Plant material and DNA extraction}

The experimental materials used in the present study consisted of 38 durum wheat (Triticum turgidum L. subsp. durum [Desf.] Husn) populations that were mainly collected from different zones of Iran. The Iranian populations represented 11 populations from the West and North-West, 12 populations from the North-East and eight populations from South-West Iran. The remaining populations included two populations from Italy, one from Mexico and four from Iran with unknown origin (Table 1, Fig. 1). DNA was extracted from a bulk sample of 10 young seedlings per accession using the cetyltrimethylammonium bromide-based protocol of Murray and Thomson (1980) with minor modifications. The quality of the DNA was estimated by both spectrophotometry (260/280 ratio) and gel electrophoresis ( $0.8 \%$ agarose gel).

\section{SCoT analysis}

Ten ScoT primers deveoped by Collard and Mackill (2009b) were used for genetic diversity analysis in durum genotypes (Table 2). For optimization, PCR amplification was performed in a $20 \mu \mathrm{L}$ reaction mixture containing $1 \times$ PCR buffer, $30 \mathrm{ng}$ sample DNA, $0.2 \mathrm{mM}$ dNTPS, $0.3 \mu \mathrm{M}$ of primer and $1 \mathrm{U}$ of Taq polymerase (Cinnagene, Iran). PCR programmes were carried out in a Eppendorf thermocycler as follows: $94{ }^{\circ} \mathrm{C}$ for $2 \mathrm{~min}$, followed by 38 cycles of denaturation at $93{ }^{\circ} \mathrm{C}$ for $30 \mathrm{~s}$, annealing at $48{ }^{\circ} \mathrm{C}$ for $30 \mathrm{~s}$,

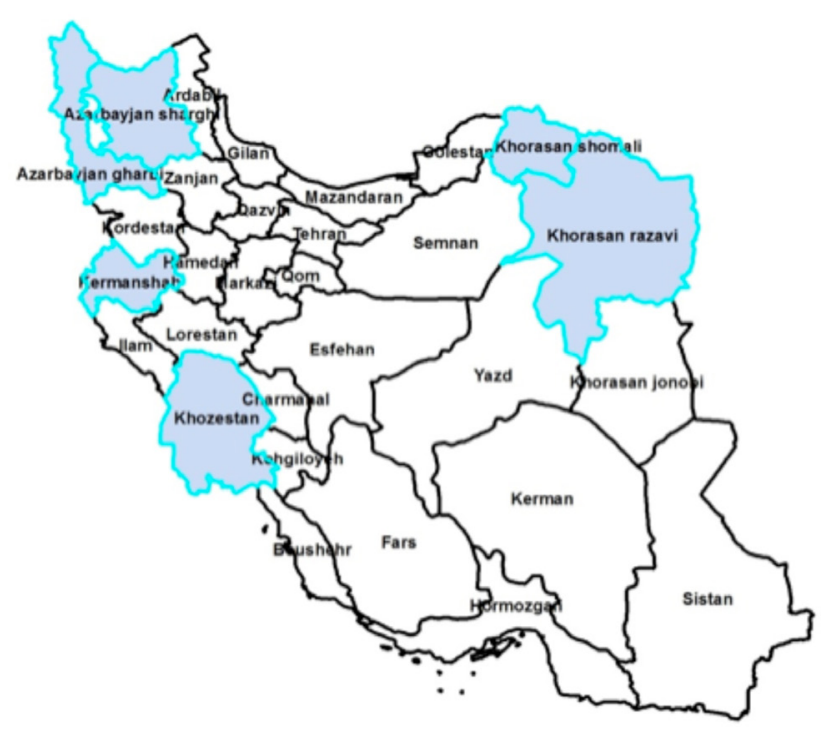

Fig. 1. Map of Iran showing the approximate areas where landrace durum wheat accessions used in this study were collected. 
Table 2. Primers used in SCoT analysis. Annealing temperature was $48^{\circ} \mathrm{C}$ for all primers

\begin{tabular}{|llc|}
\hline Primer & Sequemces (5' to 3') & GC\% \\
SCoT1 & caacaatggctaccacca & 50 \\
\hline SCoT2 & caacaatggctaccaccc & 55 \\
\hline SCoT11 & aagcaatggctaccacca & 50 \\
\hline SCoT12 & acgacatggcgaccaacg & 61 \\
\hline SCoT13 & acgacatggcgaccatcg & 61 \\
\hline SCoT20 & accatggctaccaccgcg & 66 \\
\hline SCoT22 & aaccatggctaccaccac & 55 \\
\hline SCoT28 & ccatggctaccaccgcca & 66 \\
\hline SCoT35 & catggctaccaccggcc & 72 \\
\hline SCoT36 & gcaacaatggctaccacc & 55 \\
\hline
\end{tabular}

and extension at $72{ }^{\circ} \mathrm{C}$ for $80 \mathrm{~s}$. A final extension cycle at 72 ${ }^{\circ} \mathrm{C}$ for 10 min was followed. PCR products were separated on $1.4 \%$ agarose gels and stained with ethidium bromide.

\section{CDDP analysis}

The sequences of 10 CDDP primers employed in the present study were based on the protein sequences of wellcharacterized genes (Collard, Mackill 2009a) from diverse plant species (Table 3 ).

PCR was performed in a total reaction volume of $20 \mu \mathrm{L}$ containing $50 \mathrm{ng}$ sample DNA, $0.2 \mathrm{mM}$ dNTPS, $0.3 \mu \mathrm{M}$ of primer and $1 \mathrm{U}$ of Taq polymerase (Cinnagene, Iran). Amplifications were programmed for an initial step at 95 ${ }^{\circ} \mathrm{C}$ for $3 \mathrm{~min}$, followed by 38 cycles of denaturation at 94 ${ }^{\circ} \mathrm{C}$ for $30 \mathrm{~s}$, annealing at the required $\mathrm{Tm}$ for $30 \mathrm{sec}$ and elongation at $72{ }^{\circ} \mathrm{C}$ for $90 \mathrm{~s}$, followed by a final elongation step at $72^{\circ} \mathrm{C}$ for $10 \mathrm{~min}$. PCR products were analyzed using $1.2 \%$ agarose electrophoresis gels stained with ethidium bromide.

\section{Data analysis}

A binary matrix reflecting SCoT/CDDP band presence (1) or absence (0) was generated. Nei genetic distance (Nei 1973) was determined among the genotypes and used for grouping of the genotypes by unweighted neighbor joining (NJ) cluster method (Perrier et al. 2003). Tree construction following unrooted $\mathrm{NJ}$ tree using a similarity matrix was constructed using DARwin 5.0.128 (Perrier et al. 2003; Perrier, Jacquemoud-Collet, 2006) analysis. The Mantel statistic was used to compare the dissimilarity matrices as well as the dendrogrammes produced by the SCoT and CDDP markers using NTSY S software. Polymorphic information content (PIC) values were calculated for each $\mathrm{SCoT}$ and CDDP primers.

\section{Results}

\section{ScoT polymorphism and diversity pattern}

The 10 SCoT primers amplified a total of 108 amplicons with a range of nine to 13 bands per primer, of which 70 (64\%) were polymorphic (Table 4). Percent polymorphism varied from 46 to $83 \%$, with 4 to 10 polymorphic bands per primer. The primer SCoT28 exhibited the highest number of polymorphic bands (10). Polymorphism information content (PIC) ranged from 0.27 (SCoT12) to 0.43 (SCoT28) with an average of 0.35 . Based on the UNJ clustering method, the 38 durum wheat genotypes genotypes grouped into two major groups (Fig. 2). Cluster I consisted of 20 genotypes that all of them originated from West, NorthWest and North-east Iran. The second cluster consisted of remained genotypes, all with origin from South Iran. Also the genotypes with unknown sources from Iran and two genotypes from Italy and one from Mexico grouped in this cluster (Fig. 2).

Table 3. Conserved DNA sequence targets and CDDPs primer sequences and details

\begin{tabular}{|c|c|c|c|c|c|c|}
\hline Gene & Gene function & $\begin{array}{l}\text { Amino acid } \\
\text { motif }\end{array}$ & $\begin{array}{c}\text { Primer } \\
\text { name }\end{array}$ & Sequence (5' to $\left.3^{\prime}\right)$ & GC (\%) & $\begin{array}{l}\text { Annealing } \\
\text { temperature } \\
\left({ }^{\circ} \mathrm{C}\right)\end{array}$ \\
\hline \multirow[t]{2}{*}{ ABP1 } & Auxin-binding protein & TPIHR & ABP1-1 & acsccsatccaccgc & 73 & 50 \\
\hline & & HEDVQ & ABP1-3 & cacgaggacctscagg & 69 & 51 \\
\hline \multirow[t]{2}{*}{ WRKY } & $\begin{array}{c}\text { Transcription factor for developmental and } \\
\text { physiological roles }\end{array}$ & WRKYGQ & WRKYR1 & gtggttgtgtcttgcc & 60 & 52 \\
\hline & & GKHNH & WRKYF1 & tggcgsaagtacggccag & 67 & 53 \\
\hline \multirow[t]{2}{*}{ MYB } & $\begin{array}{c}\text { Unknown (implicated in secondary } \\
\text { metabolism, abiotic and bioticnstresses, cellular } \\
\text { morphogenesis) }\end{array}$ & GKSCR & Myb1 & ggcaagggctgccgc & 80 & 54 \\
\hline & & GKSCR & Myb2 & ggcaagggctgccgg & 80 & 55 \\
\hline \multirow[t]{2}{*}{ ERF } & $\begin{array}{l}\text { Transcription factor involved in plant disease } \\
\text { resistance pathway }\end{array}$ & HYRGVR & ERF1 & cactaccccggsctscg & 77 & 56 \\
\hline & & AEIRDP & ERF2 & gcsgagatccgsgaccc & 77 & 57 \\
\hline \multirow[t]{2}{*}{ KNOX } & $\begin{array}{l}\text { Homeobox genes that function as transcription } \\
\text { factors with a unique homeodomain }\end{array}$ & KGKLPK & Knox1 & aagggsaagctsccsaag & 61 & 58 \\
\hline & & HWWELH & Knox2 & cactggtgggagctscac & 67 & 59 \\
\hline
\end{tabular}


Table 4. Chemical Total number of amplified bands (TB), polymorphism bands (PB), percentage of polymorphism bands (PPB) and PIC values in durum wheat accessions as revealed by SCoT and CDDP markers

\begin{tabular}{|c|c|c|c|c|c|}
\hline & Marker & TB & PB & PPB & PIC \\
\hline \multirow[t]{10}{*}{ SCoT } & SCoT28 & 12 & 10 & 83 & 0.43 \\
\hline & SCoT35 & 10 & 6 & 60 & 0.34 \\
\hline & SCoT13 & 11 & 8 & 72 & 0.37 \\
\hline & SCoT 1 & 13 & 10 & 77 & 0.41 \\
\hline & SCoT36 & 10 & 6 & 60 & 0.31 \\
\hline & SCoT2 & 11 & 7 & 64 & 0.36 \\
\hline & SCoT12 & 9 & 4 & 44 & 0.27 \\
\hline & SCoT22 & 10 & 6 & 60 & 0.33 \\
\hline & SCoT20 & 12 & 7 & 58 & 0.36 \\
\hline & SCoT11 & 10 & 6 & 60 & 0.35 \\
\hline \multirow[t]{10}{*}{ CDDP } & ABP1-1 & 12 & 7 & 58 & 0.44 \\
\hline & ABP1-3 & 8 & 6 & 75 & 0.46 \\
\hline & WRKYR1 & 11 & 6 & 54 & 0.41 \\
\hline & WRKYF1 & 9 & 5 & 55 & 0.39 \\
\hline & Myb1 & 7 & 3 & 42 & 0.19 \\
\hline & Myb2 & 11 & 8 & 72 & 0.45 \\
\hline & ERF1 & 10 & 6 & 60 & 0.40 \\
\hline & ERF2 & 7 & 5 & 71 & 0.43 \\
\hline & Knoxl & 8 & 5 & 62.5 & 0.39 \\
\hline & Knox2 & 10 & 6 & 60 & 0.40 \\
\hline
\end{tabular}

\section{CCDP polymorphism and diversity pattern}

Ten CDDP primers were used to fingerprint landrace durum wheat genotypes, which generated a total of 93 bands, of which 57 were polymorphic (Table 4). The number of polymorphic bands ranged from 3 (Myb1) to 8 (Myb2) with an average 5.7 per primers. Percent polymorphism ranged from $42 \%$ to as high as $75 \%$, with an average polymorphism of $60.7 \%$ across all genotypes. PIC values ranged from 0.19 (Myb1) to 0.46 (ABP1-3), with an average value of 0.39 per primer (Table 4 ). Based on the unweighted neighbour-joining method, the 38 durum wheat genotypes grouped in three distinct clusters (Fig. 3). Cluster

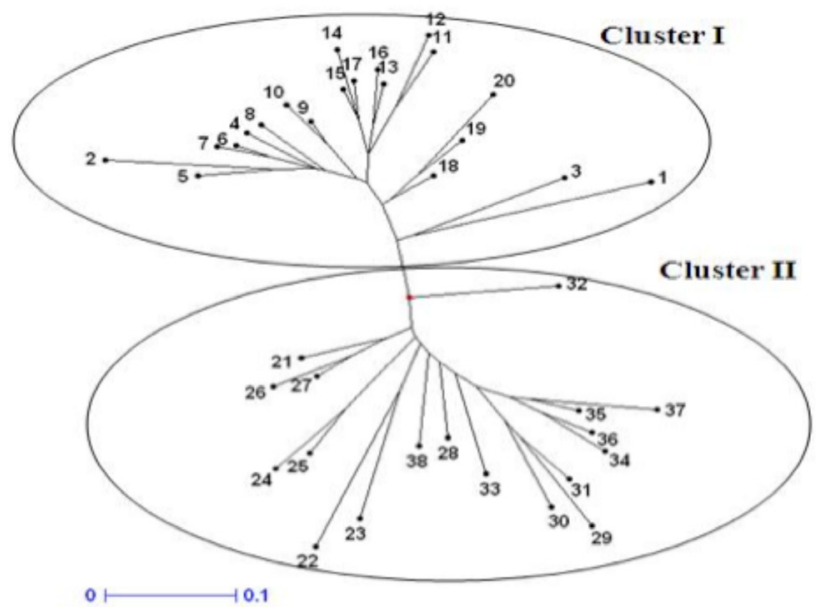

Fig. 2. Dendrogram of the 38 Iranian durum wheat landraces based on the dissimilarity matrix developed using SCoT markers.
I comprised 19 genotypes e from West and North-West of Iran. Cluster II contained 13 genotypes from North-West and South Iran. Remaining genotypes grouped in a third cluster that originated from Iran and Italy (Fig. 3).

\section{Comparison between the SCOT and CDDP marker systems}

The present study showed that both marker systemes can be effective in estimating genetic diversity in durum wheat genotypes, as shown by the high polymorphic percentage and PIC values. In generall, CDDP markers generated higher polymorphism and PIC values than for the SCoT markers. The cophenetic coefficient for both markers

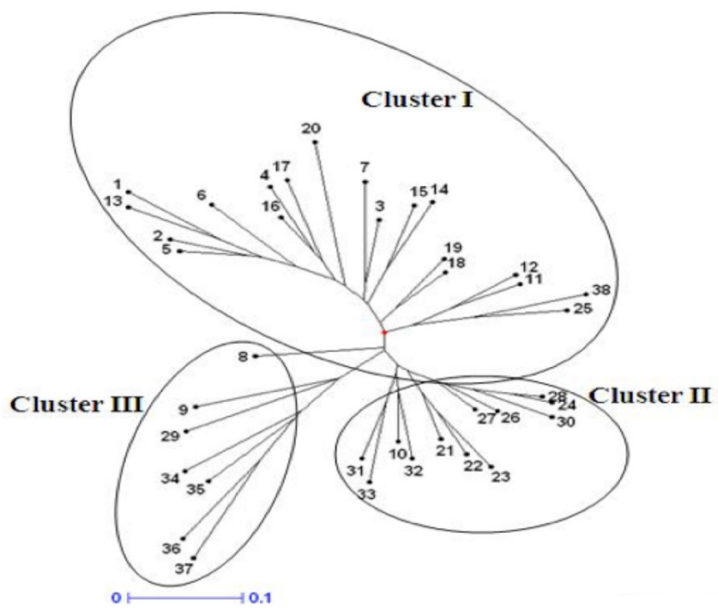

Fig. 3. Dendrogram of the 38 Iranian durum wheat landraces based on the dissimilarity matrix developed using CDDP markers. 
systems ( $\mathrm{SCoT}=0.78$ and CDDP $=0.82)$ indicated good fit for clustering. The values of mantel test correlation showed a positive correlation $\left(r=0.63^{\star}\right)$ between the marker types.

\section{Discussion}

Characterization of potential genome diversity of germplasm collections requires better knowledge of its genetic diversity. Knowledge of the extent of crop genetic variability and the association of specific traits with geographic origin not only facilitates breeding programmes but also estimates the needs for future collection of germplasm (Talebi et al. 2012).

In the present study, we compared genetic diversity of durum wheat landraces originating from Iran by using SCoT and CDDP markers of functional domains of wellcharacterised plant genes (Collard, Mackill 2009a; b). Several authors also reported that these marker techniques were able to provide more reliable diversity information compare to RAPD or ISSR techniques (Amirmoradi et al. 2012; Li et al. 2013; Poczai et al. 2013) and are useful as tools for studying the genetic diversity of different plant germplasm. There have been previous reports on clustering of genotypes using gene-based molecular markers in potato (Gorji et al. 2011), chickpea (Pakseresht et al. 2013; Hajibarat et al. 2015), ramie (Satia et al. 2015), and wheat (Hamidi et al. 2014). In comparison with those studies, we found that the average polymorphism rate for SCoT and CDDP markers in Iranian durum wheat landraces were relatively high. In our study, SCoT and CDDP markers revealed independent patterns and both were effective in the characterization of diversity in landrace durum wheat accessions. Both markers showed high polymorphism percent, PIC and average number of polymorphic bands per primer. We found that the efectivness of CBDP and SCoT markers was similar, but the PIC value for CDDP (0.39) was higher than for SCoT markers (0.35). Based on Mantel test results, the genetic diversity for genotypes was nearly the same using SCoT and CDDP markers.

High correlation between SCoT- and CDDP-generated polymorphism observed in this study, has been reported by Hamidi et al. (2014) in wheat and Hajibarat et al. (2015) in chickpea indicating their suitability for inferring genetic relationships, which is important in germplasm management. Although the polymorphism rate for the markers was relatively similar, we anticipate that the source of detected diversity differs, as the markers target different regions of the genome (Pakseresht et al. 2013).

We found that there was relatively low relationship between molecular divergence and geographical origin. The low correlations between genetic distances and geographical origin of the examined durum landrace accessions suggests that natural selection has not significantly affected the genome regions that were amplified by SCoT and CDDP markers or may suggest a low number of accessions and markers used in this study. On the other hand, the poor relationship between molecular divergence and geographical origins may reflect that accessions from one place entered into more than one cluster. Conversely, accessions from different geographical origins were relatively unique and tended to be clustered in one part of the dendrogram, which suggests that the most of the differences observed between accessions is determined not only by environmental differences but also by genetic factors.

The present study showed high genetic diversity in Iranian landrace durum wheat germplasm accessions. The magnitude and pattern of genetic variation detected in this study can be useful for more systematic germplasm management and utilization in breeding programmes (Tanya et al. 2011). The exploitation of crosses between genetically distant parents (e.g., recombinants parents from the local accessions and the introduced genotypes) and those from diverse local sources may produce higher heterosis, better genetic recombination and segregation in their progenies and result in varieties with broad genetic base (Chahal, Gosal 2002). The selection of genotypes for this study is primarily based on different geographic origin and also the important role of selected zones of Iran in wheat production for poor farmers. Therefore, we believe that there is a need for molecular markers based studies as a complementary study for better understanding the diversity pattern in Iranian durum germplasm. It will reduce the amount of materials for study as well as the costs of experiments.

Future germplasm collection and utilization strategies should take into consideration the magnitude and pattern of genetic diversity indicated by the present investigation. It is expected that when such diverse genotypes are involved in breeding programmes, as a result of reshuffling of the alleles due to recombination, there are better chances for the appearance of transgressive segregation with beneficial traits that can be selected to extract high yielding lines with desirable trait combination (Sofalian et al. 2008; Pakseresht et al.2013). For the first time, we demonstrated the capability of SCoT and CDDP in estimaion not only for determining the polymorphism rate, but also for the management of genetic diversity in Iranian durum wheat landraces and their uses in applied breeding programmes, particularly for the development of a core collection. In conclusion, two marker methods used, which targeted certain parts of plant genome or candidate plant genes by primer design, were used to estimate diversity durum wheat. This information is valuable for germplasm classification and defining various/ heterotic groups, which is particularly important in hybrid/ cross-breeding programmes for wheat.

\section{References}

Amirmoradi B., Talebi R., Karami E. 2012. Comparison of genetic variationand differentiation among annual Cicer species using start codon targeted(SCoT) polymorphism, DAMD-PCR, 
and ISSR markers. Plant Syst. Evol. 298:1679-1688.

Chahal G.S., Gosal S.S. 2002. Principles and Procedures of Plant Breeding: Biotechnological and Conventional Approaches. Narosa, New Delhi.

Collard B.C.Y., Mackill D.J. 2009a. Conserved DNA-derived polymorphism (CDDP): a simple and novel method for generating DNA markers in plants. Plant. Mol. Biol. Rep 27: $558-562$

Collard B.C.Y., Mackill D.J. 2009b. Start codon targeted (SCoT) polymorphism: a simple, novel DNA marker technique for generating gene-targeted markers in plants. Plant. Mol. Biol. Rep. 27: 86-93.

Fayaz F., Mardi M., Aghaee M., Darvish F., Talebi R. 2013. Phenotypic diversity analysis of grain yield and yellow pigment content in germplasm collected from Iranian durum wheat (Triticum turgidum L.) landraces. Arch. Agron. Soil. Sci. 59: $1339-1357$

Hajibarat Z., Saidi A., Hajibarat Z., Talebi R. 2015. Characterization of genetic diversity in chickpea using SSR markers, start codon targeted polymorphism (SCOT) and conserved DNA-derived polymorphism (CDDP). Physiol. Mol. Biol. Plant. 21: 365-373

Hamidi H., Talebi R., Keshavarzi F. 2014. Comparative efficiency of functional gene-based markers, start codon targeted polymorphism (SCoT) and conserved DNA-derived polymorphism (CDDP) with ISSR markers for diagnostic fingerprinting in wheat (Triticum aestivum L.). Cereal. Res. Commun. 42: 558-567.

Harlan J.R. 1986. Plant domestication: diffuse origins and diffusion. In Barigozzi C. (ed) The Origin and Domestication of Cultivated Plants. Elsevier, Amsterdam, pp. 21-34.

Heikrujam M., Kumar J., Agrawal V. 2015. Genetic diversity analysis among male and female Jojoba genotypes employing gene targeted molecular markers, start codon targeted (SCoT) polymorphism and CAAT box-derived polymorphism (CBDP) markers. Meta Gene 5: 90-97.

Li T., Guo J., Li Y., Ning H., Sun X., Zheng C. 2013. Genetic diversity assessment of chrysanthemum germplasm usingconserved DNA-derived polymorphism markers. Sci. Hortic. 162: 271277.

Maccaferri M., Stefanelli S., Rotondo F., Tuberosa R., Sanguineti M. C. 2007.Relationships among durum wheat accessions. I. Comparative analysis ofSSR, AFLP, and phenotypic data. Genome 50: 373-384.

Mardi M., Naghavi M.R., Pirseyedi S.M., Kazemi Alamooti M., Rashidi Monfared S., Ahkami A.H., Omidbakhsh M.A., Alavi N.S., Salehi Shanjani P., Katsiotis A. 2011. Comparative assessment of SSAP, AFLP and SSR markers for evaluationof genetic diversity of durum wheat (Triticum turgidum L. var. durum). J. Agric. Sci. Tech. 13: 905-920

Medini M., Hamza S., Rebai A., Baum M. 2005. Analysis of genetic diversity in Tunisian durum wheatcultivars and related wild species by SSRand AFLP markers. Genet Resour. Crop Evol. 52: 21-31.

Murray M.G., Thomson W.F. 1980. Rapid isolation of high molecular weight plant DNA. Nucleic Acids Res. 8: 4321-4325.

Nei M. 1973. Analysis of gene diversity in subdivided populations. Proc. Natl. Acad. Sci. USA 70: 3321-3323

Oliveira H.R., Campana M.G., Jones H., Hunt H.V., Leigh F., Redhouse D.I., Lister D.L., Jones M.K. 2012. Tetraploid wheat landraces in the Mediterranean basin: taxonomy, evolution and genetic diversity. PLos One 7: e37063.

Pakseresht F., Talebi R., Karami E. 2013. Comparative assessment of ISSR, DAMD and SCoT markers for evaluation of genetic diversity and conservation of chickpea (Cicer arietinum L.) landraces genotypes collected from north-west of Iran. Physiol. Mol. Biol. Plant. 19: 563-574

Perrier X., Flori A., Bonnot F. 2003. Data analysis methods. In: Hamon P., Seguin M., Perrier .X, Glaszmann J.C. (eds) Genetic Diversity of Cultivated Tropical Plants. Science Publishers, Enfield, Montpellier, pp. 43-76.

Perrier X., Jacquemoud-Collet J.P. 2006. DARwin software, http:// darwin.cirad.fr/darwin

Poczai P., Varga I., Laos M., Cseh A., Bell N., Valkonen J.P.T., Hyvönen J. 2013. Advances in plant gene-targeted and functional markers: a review. Plant. Methods 9: 6.

Satya P., Karana M., Jana S., Mitra S., Sharma A., Karmakar P.G., Rayb D.P. 2015. Start codon targeted (SCoT) polymorphism reveals genetic diversity in wild anddomesticated populations of ramie (Boehmeria nivea L. Gaudich.), a premium textile fiber producing species. Meta Gene 3: 62-70.

Smale M., Reynolds M.P., Warburton M., Skovmand B., Trethowan R., Singh R.P., Ortiz-Monasterio I. Crossa J. 2002. Dimensions of diversity in modern spring bread wheat in developing countries from 1965. Crop. Sci. 42: 1766-1779.

Sofalian M., Chaparzadeh N., Javanmard A., Hejazi M.S. 2008. Study the genetic diversity of wheat landraces from northwest of Iran based on ISSR molecular markers. Int. J. Agric. Biol. 10: 466-468

Soleimani V.D., Baum B.R., Johnson D.A. 2002. AFLP and pedigree-based genetic diversity estimates in modern cultivarsof durum wheat (Triticum turgidum L. subsp. durum (Desf.) Husn.). Theor. Appl. Genet. 104: 350-357

Talebi R., Fayyaz F., Karami M. 2012. Morphometric and amplified fragment length polymorphism marker analysis in some landrace wheat (Triticum aestivum L.) genotypes collected from north-west of Iran. Environ. Exp. Biol. 10: 49-56.

Tanksley S.D., McCouch S.R. 1997. Seed banks and molecular maps: unlocking genetic potential from the wild. Science 277 : 1063-1066.

Tanya P., Taeprayoon P., Hadkam Y., Srinives P. 2011. Genetic diversity among Jatropha and Jatropha-related species based on ISSR markers. Plant. Mol. Biol. Rep. 29: 252-264. 